\title{
Use of Social Network Sites (SNS) by Library Academics in the Workplace: Perspectives of University Librarians in Sri Lanka
}

Sureni Weerasinghe ${ }^{1}$, B.M.M.C.B. Hindagolla ${ }^{2}$

\begin{abstract}
Libraries and in particular, university libraries around the globe are constantly revolutionized due to technological advancements which provide rich opportunities for libraries to embed blends of innovations into the work environment and render better services for their user communities. This research attempted to render views of library academics with regard to their current use of Social Network Sites (SNS) in the workplace. The objectives of the study were to investigate the background of SNS use by university library academics inclusive of their usage experience, skills and frequency of use, to examine the types of SNS used by them, professional purposes as well as personal purposes for using SNS in the workplace and to investigate the access methods and user perceptions towards SNS use in the workplace. Data were gathered from a study population of 116 university librarians in Sri Lanka via the survey strategy based on a questionnaire and the data analysis was done using descriptive statistics. The key findings of the study included that the majority (78.4\%) of university librarians who participated in the survey used SNS in the workplace, respondents who had 1-5year experience in using SNS were in majority (44.8\%), a high percentage (64.7\%) of respondents assessed themselves as having "moderate experience" in using SNS, more than half $(52.6 \%)$ of the respondents felt that they possessed adequate skills to use SNS, Facebook was the social network site most frequently used by the respondents (64.7\%), most university librarians used SNS in the workplace to fulfill both professional and personal purposes, while the highest percentage of university librarians (58.6\%) used SNS in the workplace for the specific professional purpose of "interacting with co-workers and professionals in the field" and the highest percentage of them (47.4\%) used SNS for the specific personal purpose of
\end{abstract}

1 Assistant Librarian, University of Peradeniya. Email: sureniw@pdn.ac.lk, D https://orcid.org/0000-0001-7337-8408

2 Senior Assistant Librarian, University of Peradeniya. Email: menakah@pdn.ac.lk, https://orcid.org/0000-0002-4358-6035

Received: 2 April 2018, Accepted revised version: 2 July 2018. 
"personal contact", and the majority of them used the university network to access SNS in the workplace. Sri Lankan university librarians should keep pace with new innovative technologies such as SNS to remain worthy and important in this competitive digital world.

Keywords: Library academics, Sri Lanka, Social network sites-Usage, University libraries, Workplace 


\section{Introduction}

Information and Communication Technology (ICT) which is a strategic tool that render prosperity plays an integral role in organizations and more specifically in university libraries that strive to achieve goals of quality, efficiency and effectiveness (Kripanont, 2007). Emerging new technologies has revolutionized the way information is being disseminated, packaged, processed and stored, as well as how information is sought and assessed by users. The mission of a university library is to support their university facilitating as a focal point for the provision of standard information to the learning, teaching and research communities. University sector libraries around the globe are facing constant changes due to technological advancements. One major impact of ICT on libraries is the proliferation of social media applications in the workplace (Mishra, 2008; Sahoo \& Sharma, 2015). Social media is "a group of Internet-based applications that build on the ideological and technological foundations of Web 2.0, and that allow the creation and exchange of user generated content" (Kaplan \& Haenlein, 2010, p.61). Kaplan and Haenlein (2010, p.60) have defined "six types of social media": "collaborative projects" (e.g. Wikipedia), "blogs" (e.g. Open Diary, Live Journal), "content communities" (e.g.YouTube), "social network sites" (e.g. Facebook, Twitter, and LinkedIn), "virtual game worlds" (e.g. World of Warcraft) and "virtual social worlds" (Second Life). Social media has produced important changes in libraries by rendering new ways of "providing reference, instruction, networking, outreach, cataloguing, searching, document delivery, and collections-related work" (Fasola, 2015, p. 870).

SNS, a type of social media, is a highly popular and rapidly advancing technology embraced by libraries including university libraries all over the globe (Chu \& Du, 2013; Jadhav, 2014). Sahoo and Sharma (2015, p.703) state that a social network site is "an online portal, or web service, which induce to building social relations among group of individuals and it connects the feelings, emotions, sharing information, and other activities of real life situation among people". MySpace, Facebook, Cyworld, professional web sites such as LinkedIn, content sites inclusive of Slideshare and Flicker and micro SNS including Twitter are some examples of SNS (Richter, Riemer, vom Brocke, \& Grobe, 2009). Other than that, 
ResearchGate, Google Scholar and Academia could be categorized under academic SNS (Palmer \& Strickland, 2007).

SNS have captured the attention of millions of users and keeping accounts in one or more SNS is one of the highly popular and increasingly growing activities on the Internet (Alarcón-del-Amo, Lorenzo-Romero, \& DelChiappa, 2014). SNS instantly transfer information to users through iphones, Blackberries and laptops (Lane \& Coleman, 2012). The attention of academic researchers is also increasingly attracted by SNS which can be employed to fulfill their personal, educational as well as work-related purposes.

Effective use of SNS will enable libraries and in particular university librarians to reap various advantages such as the promotion of library services and resources, updating library refurbishments and promoting events and new acquisitions (Taylor \& Francis, 2014). Also, Fasola (2015) outlines that social media platforms offer libraries new ways to render instruction, user outreach, searching, document delivery, cataloguing and collections-related work. In addition, these social technologies enable library professionals to exchange information, ideas and opportunities as well as to keep up to date with new knowledge and resources related to their profession (Chu \& Du, 2013; Suraweera et al., 2013). SNS are of viable means to connect with a large user base in a short span of time. The library users will be enticed to utilize library services via the empowerment they gain by SNS for the active participation and communication with library staff (Fasola, 2015). Bennett, Owers, Pitt, and Tuker (2010) highlight in their study that SNS can increase workplace productivity by enhancing employee cooperation and communication that support knowledge transfer. Therefore, it is vital that university librarians in developing countries such as Sri Lanka also adapt to these technologies and keep pace with the changing role of librarianship in the digital era.

Most of the studies conducted on using SNS and social media in libraries have focused on using SNS as a marketing tool or for promoting library services. However, this study focuses on the library academics and their general use of SNS in the workplace. That is, the use of SNS in the 
workplace for professional as well as personal purposes such as for research purposes, interaction, enhancing personal knowledge, communication, user service provision etc. Most studies revealed through literature had restricted SNS use by librarians to the context of marketing and service provision whereas the current study does not attempt to impose such restriction. It is important for library academics to be in par with new technologies such as SNS to prove themselves worth against numerous information providers in this competitive digital world, where the value of libraries and librarians are constantly being questioned. Regardless of the benefits of SNS, there seems to be a lag in embracing these social technologies at a considerable pace in certain countries, specifically in developing countries (Chitumbo, 2015). Few studies conducted in Sri Lanka have revealed low usage of SNS in university sector libraries (Gamage, 2012; Amarakoon \& Seneviratne, 2014). It is important that Sri Lankan university libraries integrate SNS to render effective user services as well as to develop employee productivity. Implementation of new emerging technologies such as SNS will pave the way for library academics in Sri Lanka -a country still in the developing stage- to break the walls of traditional library system and to reach modern users in the digital environment. This study will help to motivate university librarians in Sri Lanka to practice the effective use of SNS in their workplace.

\section{Research Objectives}

This research attempted to render views of library academics with regard to their current use of SNS in university libraries. The objectives of the study were to:

i. Investigate the extent to which university library academics currently use SNS in the workplace including their usage experience, skills and frequency of use

ii. Examine the types of SNS used by university library academics and the professional as well as personal purposes for their use of SNS in the workplace

iii. Investigate the access methods and user perceptions towards SNS use in the workplace. 


\section{Literature Review}

Several studies with regard to the use of social media and SNS in libraries have been carried out all over the globe. Priolkar and Kumbhar (2014) explored the use of SNS by LIS professional, purposes for their use and how SNS were useful for enhancing library services. Data collection was done via a survey using a structured questionnaire and the research subjects were 25 library professionals from 10 government institutes. The key findings of the study included that majority of library professionals were daily users of SNS, they frequently used Facebook; the respondents mostly used SNS for chatting and to interact with their professional friends, most respondents found SNS useful to gain study related information and the majority of them believed that SNS had a great impact on the LIS profession. The authors concluded that library professionals were aware of the use of SNS and they were able to render new services via SNS (Priolkar \& Kumbhar, 2014). In a similar study, Kaushik (2016) attempted to examine the use of SNS tools and services by LIS professionals. The findings of the study included that majority of LIS professionals who participated in his survey were working in academic libraries; most of them were aware of SNS tools and services; majority knew about SNS via Internet search engines, most of them used SNS several times a day and the purpose was to interact with users and to get user feedback (Kaushik, 2016). Further, it was revealed that the majority of LIS professionals used Facebook for marketing of library services but there was no policy established for the use of SNS in libraries (Kaushik, 2016).

In line with the above studies, Hamad, Tbaishat and Al-Fadel (2016) focused on the librarians' perceptions towards the role played by social networks in the enhancement of professional skills and how they used social networks for library service promotion. This was a case study designed in the real organizational context of two academic libraries. Questionnaires were used to gather data from the library staff members $(n=165$, response rate=93.9\%). The findings revealed that the respondents were highly aware of social networks and extensively used these for professional development. Yet, it was seen that social networks were not completely exploited in the promotion of library services (Hamad, Tbaishat \& Al-Fadel, 2016). Further, "job title" was the only factor which had an influence on the results. In conclusion the authors outlined that academic libraries in Jordan should more 
effectively use social networks for the promotion of library services. Bhardwaj (2014) also studied how LIS professionals in higher education institutions incorporated SNS into their daily work. It was found that most of the respondents were members of the official group on the SNS and that LIS professionals used SNS to socialize, to be updated, seek for jobs and to obtain information related to conferences and seminars in their study disciplines (Bhardwaj, 2014). In addition, the author found privacy and cyber bullying as certain legitimate concerns of LIS professionals (Bhardwaj, 2014).

Chen, Chu, and Xu (2012) examined how libraries could effectively interact with users via social networking sites. In this study, four types of interactions (knowledge sharing, information dissemination, communication and knowledge gathering) were taken into consideration. It was found that knowledge sharing was the interaction which the majority of users was engaged. The authors suggested that libraries should employ various types of SNS and take into consideration the properties of their communities to efficiently interact with users on SNS (Chen et al., 2012). Islam and Habiba (2015) focused on the use of social media for library marketing by 46 libraries in Bangladesh. It was revealed that most of the libraries utilized Facebook and LinkedIn to market library services. In addition, it was observed that the majority of libraries used "social media for marketing library product and services, for sharing library news and events, video conferencing, advertisement and research work" (Islam \& Habiba, 2015, p. 303). In another study, Zohoorian-Fooladi and Abrizah (2014) stressed on the social media presence of academic libraries in Malaysia. Data were collected by means of three focus group studies using 22 librarians from three universities. Findings exhibited that, four kinds of social media inclusive of blogs, multimedia sharing sites, social bookmarking and social networking sites were used in libraries for user outreach. Also, it was observed that librarians used social media for promoting library services, managing organizational knowledge and to obtain user feedback instantly. The study rendered evidence that Malaysian academic libraries had not fully exploited the benefits of social media and the authors recommended that the library management take effective actions to create social media presence in these libraries (Zohoorian-Fooladi \& Abrizah, 2014). 
Although there are numerous studies conducted to explore social media use among various user categories, there is little evidence of studies on the use of social media including SNS by university librarians and particularly in the context of Sri Lanka.

In the Sri Lankan context, there have been few studies engaged in examining the use of social media in libraries (Gamage, 2012; Amarakoon \& Seneviratne, 2014; Abeyrathne \& Jayasekera, 2016; Dilinika, 2015). Majority of these studies were conducted based on university sector libraries and were focused towards assessing the social media usage by the libraries as a marketing tool (Gamage, 2012; Amarakoon \& Seneviratne, 2014; Abeyrathne \& Jayasekera, 2016). These researchers found that there was a low usage of social media by university libraries in Sri Lanka, demonstrating that Sri Lankan university libraries lagged behind in using these emerging technologies as an effective marketing strategy. Amarakoon and Seneviratne (2014) observed that only $16.7 \%$ of these libraries owned a Facebook page whilst $83.3 \%$ of libraries did not own such a page. The results of the study carried out by Abeyrathne and Jayasekara (2016) indicated that out of the 15 Sri Lankan university libraries only 9 had at least a single account on a social media platform.

In a recent study, Athukorala (2017) investigated the motivational factors behind social media adoption by university library academics for marketing library resources and services. According to the findings, majority of the respondents (63.7\%) stated that their libraries have still not introduced or implemented social media while $36.3 \%$ of respondents claimed that social media had been implemented in their libraries. On the other hand, Dilinika (2015) attempted to identify how public libraries can be creative when using social media and their impact to the society.

\section{Methodology}

The survey research strategy was employed in this study. A self-designed questionnaire was used as the research tool for data collection. The questionnaire consisted of two parts: the first section spanned demographic information of the participants and it included 6 questions. The second section included questions relating to the background of SNS use in the 
workplace by the participants and it comprised of 11 questions. The study population of this study constituted of all the university librarians spanning librarians, deputy librarians, senior assistant librarians and assistant librarians within the libraries of the 15 state universities accredited to the University Grants Commission (UGC) in Sri Lanka. At the time of the survey (April 2017), the size of this population was estimated to be 124. Sampling techniques were not applied since the total study population was considered as the sample.

In order to gather data, the questionnaire was distributed among the targeted study population of 124 Sri Lankan library academics using offline and online means such as online survey via e-mail, self-administered questionnaire and posted questionnaire (posting the questionnaires to respondents who will return the filled questionnaires by post). 116 duly filled responses were returned producing a response rate of 93\%. The responses received were recorded and tabulated in Statistical Package for Social Sciences (SPSS) version 23 and data analysis was done using descriptive statistics.

\section{Results and Discussion}

\section{Demographic Characteristics}

The demographic characteristics of the library academics within university libraries of Sri Lanka were based on their gender, age category, academic position (designation), education level and work experience.

The findings from descriptive statistics associated with the respondents' demographic data indicated that that the majority of university librarians who participated in the survey were females (59.5\%), whereas $40.5 \%$ were male respondents. It shows that in Sri Lanka librarianship in the university sector has been dominated by females and that females play a key role in information service provision to the university community in Sri Lanka.

The results revealed that a substantial number of respondents belonged to the two age categories of $31-40$ years (36.2\%) and $41-50$ years (37.9\%), while $17.2 \%$ of them were between the age of 51 and 60 year (Figure 1). There were only few respondents who were less than 30 years old (4.3\%) and older 
than 60 years (4.3\%). It was interesting to observe that similar percentages of respondents belonged to both these age categories. Further, the respondents were divided into two groups as younger (40 years and below) and older subjects (over 40 years). It was seen that older subjects (59.5\%) were the larger category in comparison to younger subjects (40.5\%).

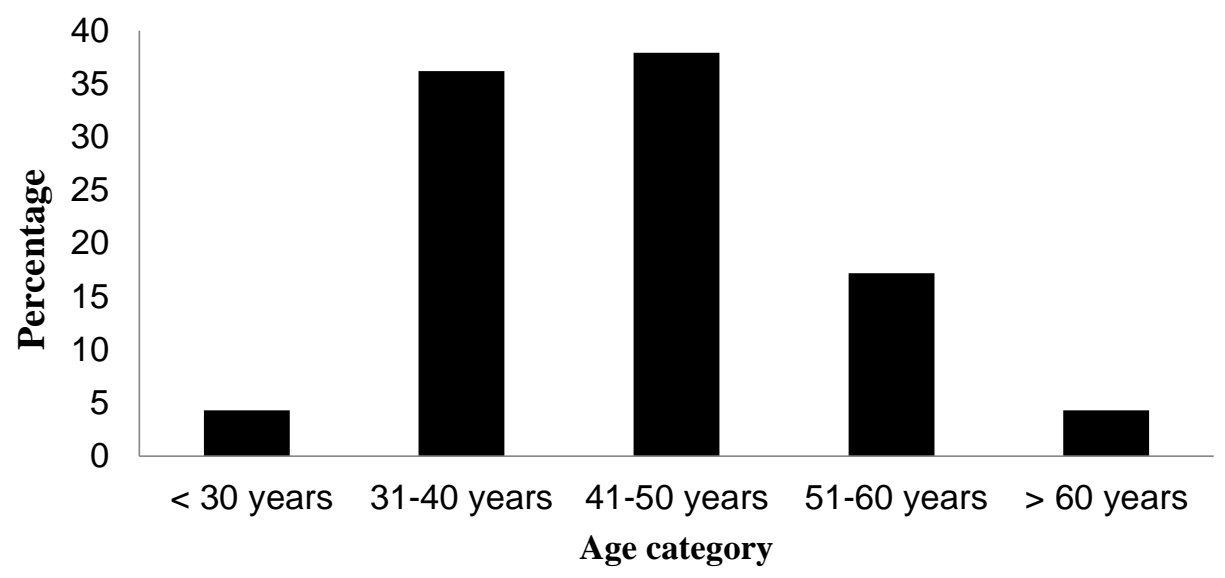

Figure 1. Distribution of the respondents by age category

With respect to the designation or current academic position of the respondents, the highest percentage (39.7\%) of respondents held the senior assistant librarian in grade 2 position (Table 1). Other than that, $28.4 \%$ were senior assistant librarians in grade 1 position, $22.4 \%$ were assistant librarians, $6.9 \%$ were librarians and only $2.6 \%$ were deputy librarians (Table 1).

Table 1. Distribution of the respondents according to their designation

\begin{tabular}{llcc} 
No. & Designation & Cases & Percentage (\%) \\
\hline 1. & Librarian & 8 & 6.9 \\
2. & Deputy Librarian & 3 & 2.6 \\
3. & Senior Assistant Librarian (Grade 1) & 33 & 28.4 \\
4. & Senior Assistant Librarian (Grade 2) & 46 & 39.7 \\
5. & Assistant Librarian & 26 & 22.4 \\
& Total & 116 & 100.0 \\
\hline
\end{tabular}


With regard to the current education level, the number of university librarians who graduated at the Masters degree level (74.1\%), far exceeded the number of those who had completed their Doctorates (12.1\%) and MPhil level (5.2\%). In addition, $8.6 \%$ of the respondents possessed only the Bachelor degree. Current education level is depicted in Figure 2.

These results demonstrate a paucity of library academics with a Doctoral degree in Sri Lankan university libraries. The knowledge and experience of university librarians who have completed Doctoral degree level will highly contribute to the provision of quality information and services to users and also facilitate the teaching and learning process.

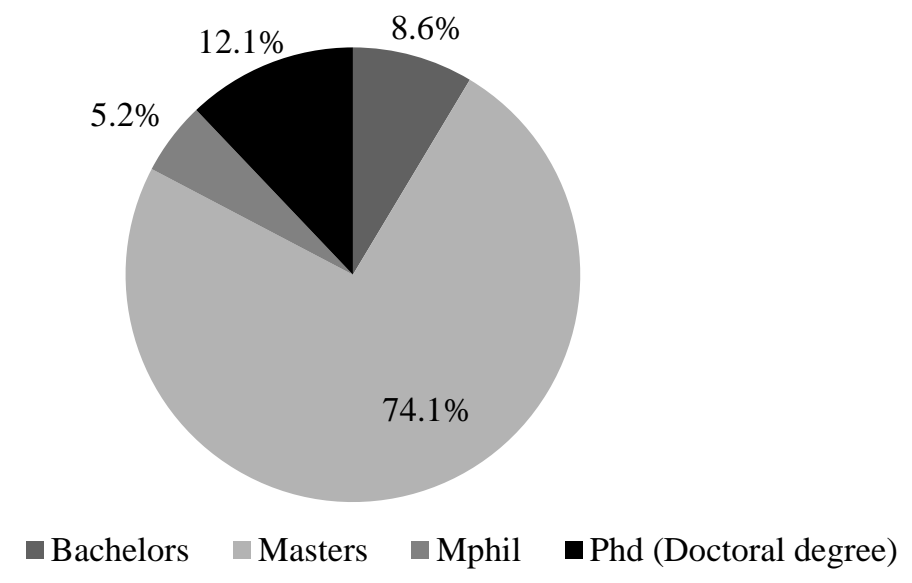

Figure 2. Education level of the respondents

Regarding the respondents' work experience as a university librarian, the highest percentage (32.8\%) of respondents reported that they had more than 15 years of work experience, whereas $26.7 \%$ of them had 5-10 years of work experience and $23.3 \%$ of them had $11-15$ years of work experience; $17.2 \%$ of respondents had work experience of less than 5 years and this group included young respondents who had joined the university librarian profession very recently (Figure 3). 


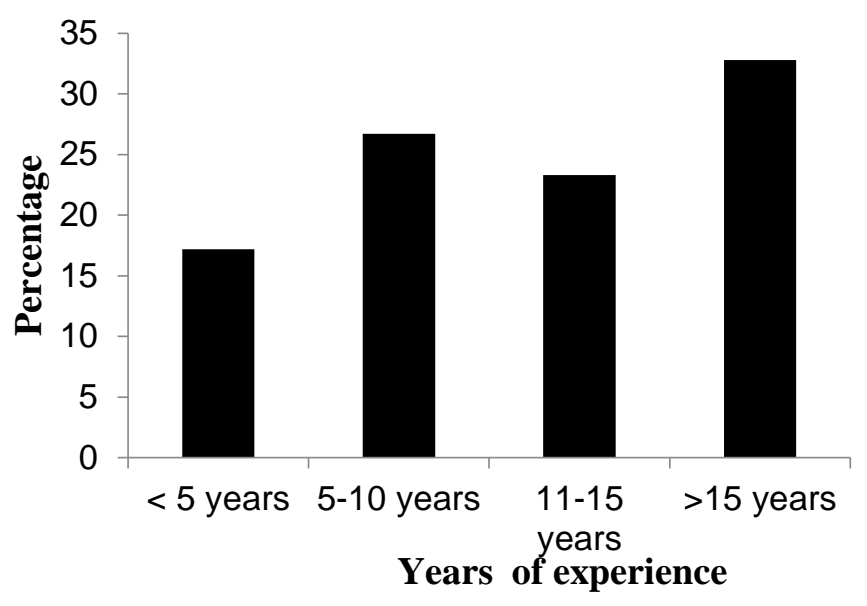

Figure 3. Work experience of the respondents

\section{Background of SNS Usage}

The respondents were asked to state whether they normally used SNS in the workplace. Majority of the respondents (78.4\%) indicated that they used SNS in the workplace, while the rest (21.6\%) of them stated that they did not use SNS in the workplace.

With regard to the users' experience in using SNS in the workplace, at the time of the survey, respondents who had used SNS in the workplace for about 1-5 years (44.8\%) were in majority when compared with those who had used SNS for less than 1 year (6.1\%); 6-10 year (24.1\%) and more than 10 years (3.4\%) (Figure 4). However, 21.6\% of the respondents reported that they had never used SNS in the workplace.

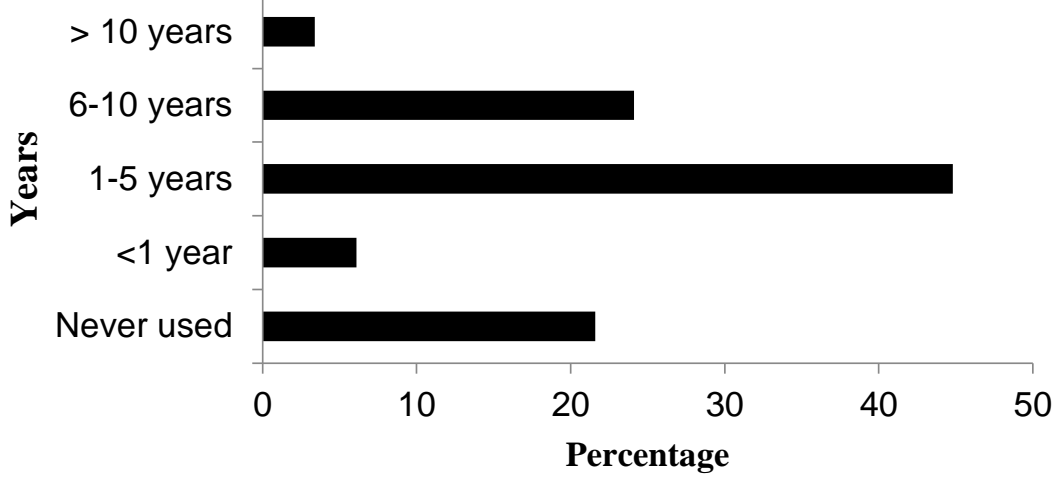

Figure 4. Experience in using SNS in the workplace 
In terms of the SNS usage frequency, findings exhibited that the greatest frequency of SNS usage in the workplace (19.8\%) was "use few times a week" (Table 2). Other than that, $14.7 \%$ of the respondents used SNS in the workplace "several times a day"; $12.1 \%$ used "about once a day"; $10.3 \%$ used "few times a month"; a similar percentage of $10.3 \%$ used "about once each week"; $5.2 \%$ used "five to six times a week"; $4.3 \%$ of respondents used SNS in the workplace "about once each month" and $1.7 \%$ of the respondents indicated that they used SNS in the workplace "according to the requirement".

Table 2. Frequency of SNS usage in the workplace

\begin{tabular}{lrc}
\hline Category & Cases & Percentage (\%) \\
\hline 1) Do not use at all & & \\
2) Use about once each month & 25 & 21.6 \\
3) Use few times a month & 5 & 4.3 \\
4) Use about once each week & 12 & 10.3 \\
5) Use few times a week & 12 & 10.3 \\
6) Use five to six times a week & 23 & 19.8 \\
7) Use about once each day & 6 & 5.2 \\
8) Use several times a day & 14 & 12.1 \\
9) Other (use as the requirement) & 17 & 14.7 \\
$\quad$ & 2 & 1.7 \\
$\quad$ Total & 116 & 100.0 \\
\hline
\end{tabular}

The participants were asked to indicate their self-assessment of using SNS. According to the results, the highest percentage of respondents (64.7\%) assessed themselves as having moderate SNS experience; 19\% of the respondents assessed themselves as having low experience in using SNS and only $16.4 \%$ assessed themselves as having high experience in using SNS.

The respondents were also asked to mention how they believed in their skills of using SNS and results are displayed in Figure 5. The findings indicated that, more than half (52.6\%) of the respondents believed that they had adequate skills to use SNS whereas $40.5 \%$ thought that they possessed skills 
"to some extent". Only $6.9 \%$ of respondents thought that they did not have enough skills to use SNS. This shows that, in this digital era some university librarians still believe that they do not have enough skills to use SNS.

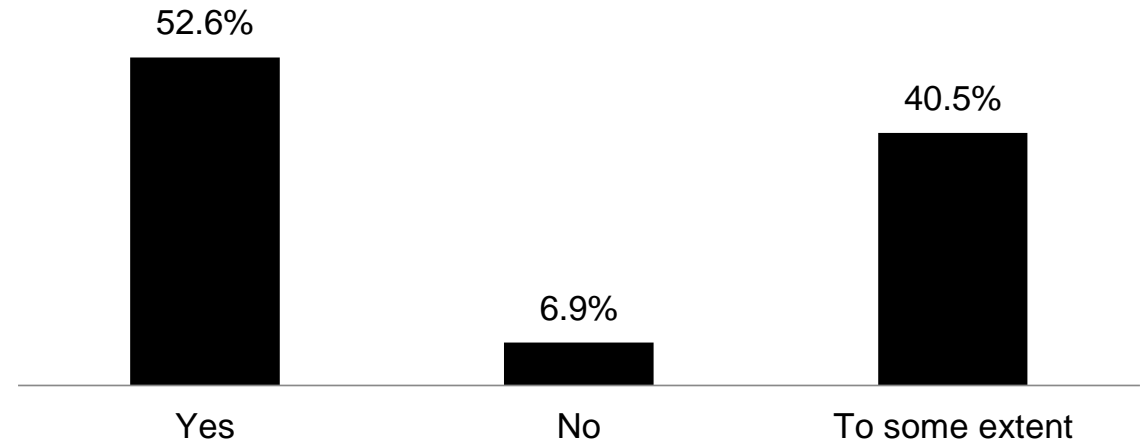

Figure 5. Response of the participants about their beliefs of having adequate skills in using SNS

Types of SNS Used by the Respondents

Figure 6 displays the details regarding the types of personal accounts maintained on SNS by the respondents. Most of respondents (89.7\%) had personal accounts on Facebook in comparison to those who had personal accounts on LinkedIn (55.2\%) and Twitter (17.2\%).

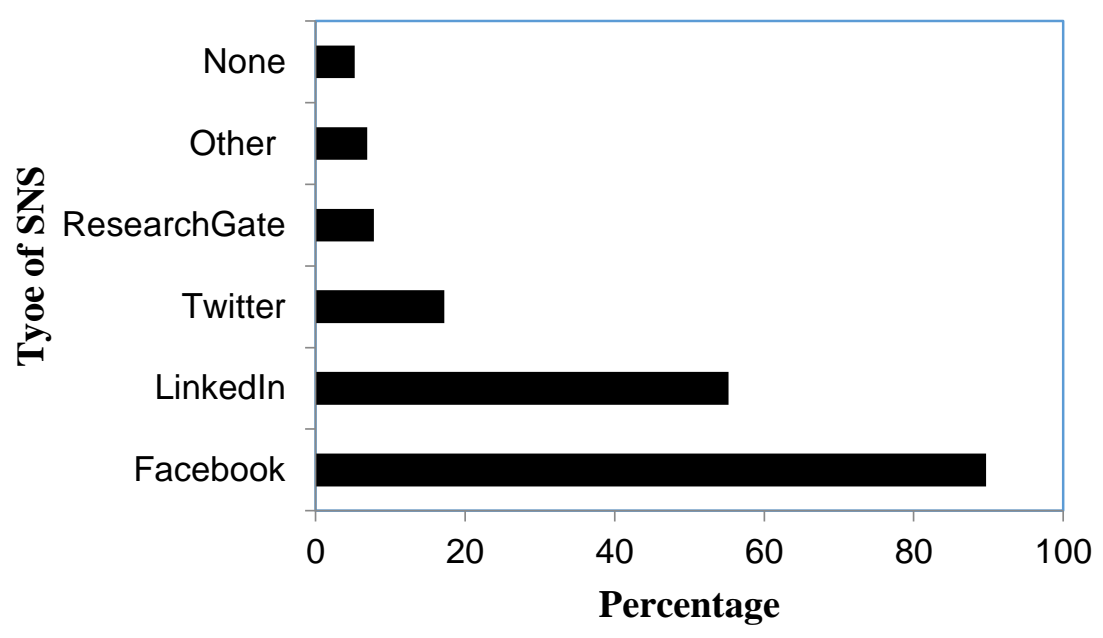

Figure 6. Type of SNS on which a personal account is maintained by the respondents 
Only $7.8 \%$ of the respondents stated that they maintained personal accounts on ResearchGate which is an academic social network site. $6.9 \%$ of the respondents stated that they had personal accounts on other types SNS which included Academia, SlideShare, Flicker, Sri Lankan equity forum and Blogger. It was also unexpected to find that $5.2 \%$ of respondents did not have personal accounts on any SNS.

Furthermore, a high percentage (64.7\%) of respondents indicated Facebook to be the most frequently used social network site in the workplace (Figure 7). Other than that, $12.1 \%$ of the respondents used LinkedIn and only $1.7 \%$ of them used ResearchGate most frequently in the workplace. The results show Facebook was the most popular social network site among Sri Lankan university librarians. However, only few of the respondents were interested in academic social network sites such as ResearchGate. This may be due to the unawareness of such social network sites which could be highly beneficial for university librarians. According to the results, more than half of the respondents had personal accounts on LinkedIn which was a professional SNS. However, only $12.1 \%$ of respondents used it most frequently. Thus, LinkedIn seemed to be somewhat popular among Sri Lankan university librarians.

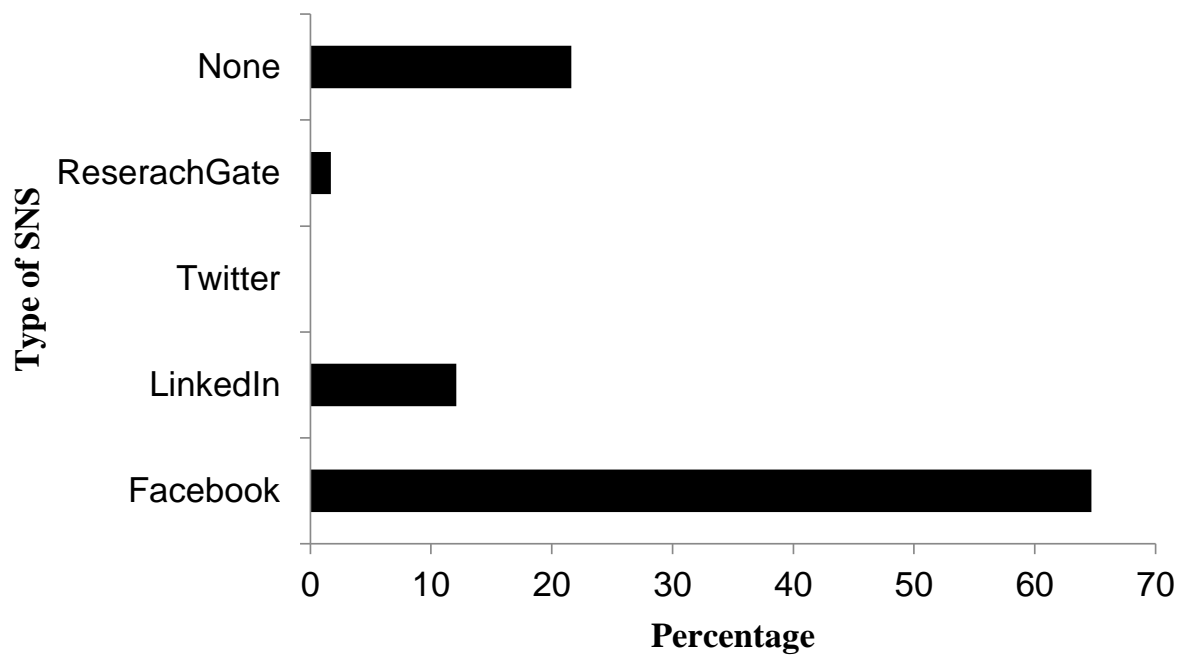

Figure 7. Most frequently used SNS in the workplace 


\section{Purpose for Using SNS}

The survey of this study explored the purposes for which SNS were used in the workplace by Sri Lankan university librarians and findings are displayed in Table 3. Findings indicated that the majority of university librarians (64.7\%) used SNS in the workplace for both professional and personal purposes, while some respondents (8.6\%) used SNS in the workplace only for professional purposes and a few (5.2\%) of them used SNS in the workplace only for personal purposes. $21.6 \%$ of the respondents reported that they did not use SNS in the workplace for any purpose.

\section{Table 3. Purposes for using SNS in the workplace}

\begin{tabular}{lrc}
\hline Purpose & Cases & Percentage (\%) \\
\hline 1) Professional purposes & 10 & 8.6 \\
2) Personal purposes & 6 & 5.2 \\
3) Both professional and personal purposes & 75 & 64.7 \\
4) Not used at all & 25 & 21.6 \\
Specific Professional Purposes & & \\
1) Library networking & 19 & 16.4 \\
2) Interacting with co-workers and professionals in & 68 & 58.6 \\
the field. & & \\
3) Marketing library resources and services & 33 & 28.4 \\
4) To provide user services & 25 & 21.6 \\
5) Research purpose & 41 & 35.3 \\
6) Knowledge sharing & 50 & 43.1 \\
7) Communicate with foreign LIS experts & 32 & 27.6 \\
8) Other (Collecting information for newsletter) & 1 & 0.9 \\
9) Do not use for any professional purposes & 31 & 26.7 \\
Specific Personal Purposes & & \\
1) Personal contact & 55 & 47.4 \\
2) Overcome stress & 14 & 12.1 \\
3) For leisure & 33 & 28.4 \\
4) Socializing & 34 & 29.3 \\
5) Enhance personal knowledge & 49 & 42.2 \\
6) Other personal purposes & 3 & 2.6 \\
7) Do not use for any personal purposes & 35 & 30.2 \\
& & \\
\hline
\end{tabular}


Further, the respondents were asked to indicate the specific professional and personal purposes for which they were using SNS in the workplace. More than half of the respondents (58.6\%) used SNS in the workplace for "interacting with co-workers and professionals in the field", whereas $43.1 \%$ used for "knowledge sharing"; $35.3 \%$ used for "research purposes"; $28.4 \%$ used for "marketing library resources and services", $27.6 \%$ used SNS to "communicate with foreign LIS experts", $21.6 \%$ used SNS to "provide user services" and $16.4 \%$ of respondents used SNS in the workplace for "library networking". One respondent used SNS to collect information for the university newsletter; $26.7 \%$ of respondents did not use SNS in the workplace for any professional purpose. With regard to the specific personal purposes of SNS use in the workplace, nearly half of the respondents (47.4\%) used SNS in the workplace for "personal contact", while $42.2 \%$ used SNS to "enhance personal knowledge"; $29.3 \%$ used for "socializing", $28.4 \%$ used "for leisure" and $12.1 \%$ used SNS in the workplace to "overcome stress". In addition, $2.6 \%$ of them stated that they used SNS in the workplace to fulfill other personal purposes such as online payments, online purchasing and for group activities (research groups and classes); $30.2 \%$ of the respondents did not use SNS in the workplace for any personal purposes.

With respect to the SNS access method, a substantial number of respondents (65.5\%) used the university network to access SNS in the workplace, while $15.5 \%$ of them used wireless connection; $23.3 \%$ of the respondents accessed SNS in the workplace through their own network connection; $21.6 \%$ of respondents did not access SNS in the workplace at all. Furthermore, 28.4\% of the respondents indicated that their university had restricted the access to the social network site, Facebook, whereas the rest of them (71.6\%) reported that no such restrictions for any SNS access were imposed by their universities (Table 4).

Finally, the respondents were asked to state their perceptions towards using SNS in the workplace. As shown in Table 5, nearly half of the respondents (49.1\%) believed that using SNS in the workplace could benefit university librarians. These positive perceptions will play a vital role in the effective implementation of SNS into Sri Lankan university library sector. 
Table 4. SNS access in the workplace

\begin{tabular}{|c|c|c|c|}
\hline Description & Category & Cases & Percentage (\%) \\
\hline \multirow[t]{4}{*}{ Access method } & 1)University network & 76 & 65.5 \\
\hline & 2) Wireless & 18 & 15.5 \\
\hline & 3) Own network connection & 27 & 23.3 \\
\hline & 4) Do not access at all & 25 & 21.6 \\
\hline \multirow{2}{*}{$\begin{array}{l}\text { Has the university } \\
\text { restricted access } \\
\text { to SNS? }\end{array}$} & 1) Yes & 33 & 28.4 \\
\hline & 2) No & 83 & 71.6 \\
\hline \multirow{2}{*}{$\begin{array}{l}\text { Types of } \\
\text { restricted } \\
\text { university }\end{array}$} & Facebook & 33 & 28.4 \\
\hline & Not applicable & 83 & 71.6 \\
\hline
\end{tabular}

Further, 37.9\% had beliefs "to some extent" towards such benefits of SNS. However, $11.2 \%$ of the respondents stated that they were "not sure" of whether SNS use in the workplace could produce benefits to university librarians and only $1.7 \%$ of them believed that the usage of SNS in the workplace was not beneficial for university librarians in Sri Lanka. The Sri Lankan culture and tradition may also influence such negative user attitudes.

Table 5. User Perceptions towards the benefit of SNS use in the workplace

\begin{tabular}{llrc}
\hline Description & Category & Cases & Percentage (\%) \\
\hline Do you believe that using & 1) Yes & 57 & 49.1 \\
SNS in the workplace could & 2) No & 2 & 1.7 \\
benefit university library & 3) To some extent & 44 & 37.9 \\
professionals in Sri Lanka? & 4) Not sure & 13 & 11.2 \\
\hline
\end{tabular}




\section{Conclusion and Recommendations}

This study provides the different perspectives of Sri Lankan university librarians with regard to the use of SNS in the workplace. It was evident from the findings of this study that the majority of university librarians in Sri Lanka used some type of SNS in the workplace. However, some respondents showed a resistance towards these social technologies. Most of the university librarians had used SNS for about 1-5 years and the majority of them used SNS "few times a week". Also, most of them assessed themselves as having "moderate experience" in using SNS while more than half of the respondents believed that they had adequate skills to use SNS. On the other hand, there were some respondents who thought that they did not have enough skills to use SNS. It is recommended that the library management should organize training sessions on the effective use of SNS to educate library academics.

Furthermore, majority of respondents had personal accounts maintained on Facebook and most of them indicated Facebook to be the most frequently used SNS in the workplace. This shows the popularity of Facebook among Sri Lankan university librarians. However, only a small percentage of them had accounts on academic SNS such as ResearchGate. These sites render an online repository for scholars to share and upload their research work. In addition, the scientific community could develop a professional online presence, interact with their peer and seek new information through these sites (Palmer \& Strickland, 2017). Awareness should be created among university librarians about academic social network sites and the benefits that could be reaped by such sites.

Most university library academics used SNS in the workplace for both professional and personal purposes, most of them used SNS for "interacting with co-workers" and for "personal contact". Majority of the university librarians accessed SNS in the workplace via the university network while some preferred to use their own connection. Some of the university librarians reported that access to Facebook was restricted by their university. However, SNS such as Facebook could be implemented for the effective use by the university community via well planned and well managed administration. Moreover, most of the respondents believed that the use of SNS in the workplace could benefit university librarians in Sri Lanka. On the contrary, 
few of them believed that Sri Lankan university librarians will not gain any benefits by using SNS in the workplace.

It is suggested that explicit and pragmatic policies should be established for using SNS for the university libraries on the basis of their user community, requirements and objectives of the library. Also, privacy and legal issues, security of information and trust on SNS use should be taken into account via thorough examination of the platforms, nature and aspects of SNS (Kaushik, 2016). Furthermore, training programs and awareness programs for library academics covering the effective use of SNS within the library, benefits and application of SNS, should be conducted.

In this digital era, provision of right information to the right users at the right time is a challenge for library academics. Therefore, emerging technologies like SNS could be used as an interactive platform by university librarians to reach their technology-savvy users in their preferred environment, breaking the barriers of the traditional library services.

\section{References}

Abeyrathne, D. K. \& Jayasekara, P. K. (2016). Do university libraries in Sri Lanka use social media as a marketing tool? Paper presented at the Peradeniya University International Research Sessions (iPURSE), University of Peradeniya, Peradeniya.

Alarcón-del-Amo, M., Lorenzo-Romero, C. \& Del Chiappa, G. (2014). Adoption of social networking sites by Italian. Information Systems and E-Business Management, 12(2), 165-187. https://doi.org/ 10.1007/s10257-013-0215-2

Amarakoon, L. R. \& Seneviratne, T. M. (2014). Social media in library marketing: Is FB being used effectively in promoting library resources and services of main university libraries in Sri Lanka? Paper presented at NILIS Research Symposium, NILIS, University of Colombo, Colombo. Retrieved from http://dl.lib.mrt.ac.lk/handle/123/10620?show=full

Athukorala, A.W.V. (2017). Motivational factors of using social media by library academics in marketing library resources and services: A study based on Sri Lankan university libraries. In S. Srinivasa Ragavan \& R. Balasubramani (Eds.), Proceedings of the UGC Sponsored International 
Conference on Knowledge Resources and Library Technologies. Department of Library and Information Science, Bharathidasan University, Thiruchirappalli.

Bennett, J., Owers, M., Pitt, M. \& Tucker, M. (2010). Workplace impact of social networking. Property Management, 28(3), 138-148.

Bhardwaj, R. K. (2014). Use of social networking sites by LIS professionals in higher education institutions in India: A study. The Reference Librarian, 55(1), 74-88.

Chen, D. Y. T. Chu, S. K. W. \& Xu, S. Q. (2012). How do libraries use social networking sites to interact with users. Proceedings of the American Society for Inf. Sci. and Tech, 49(1), 1-10.

Chitumbo, E. M. M. (2015). Social media tools for academic library services. International Journal of Humanities and Social Science Invention, 4(9), 33-40.

Chu, S. K. W. \& Du, H.S. (2013). Social networking tools for academic libraries. Journal of Librarianship and Information Science, 45(1), 6475. https://doi.org/10.1177/0961000611434361.

Dilinika, J. M. S. (2015). Impact of social media on creative libraries: with special reference to public libraries in Sri Lanka. Paper Presented at the 3rd Biennial Conference of the International Association for Asian Heritage, Centre for Asian Studies, University of Kelaniya \& International Association for Asian Heritage (IAAH), University of Kelaniya, Kelaniya.

Fasola, O.S. (2015). Perceptions and acceptance of librarians towards using Facebook and Twitter to promote library services in Oyo State, Nigeria. The Electronic Library, 33(5), 870-882. https://doi.org/10.1108/el-04-2014-0066

Gamage, R. (2012). Using Facebook for library marketing. Paper presented at the 3rd LIS Research Symposium, Department of Library and Information Science, University of Kelaniya, Kelaniya.

Hamad, F., Tbaishat, D. \& Al-Fadel, M. (2017). The role of social networks in enhancing the library profession and promoting academic library 
services: A comparative study of the University of Jordan and AlBalqaa'Applied University. Journal of Librarianship and Information Science, 49(4), 397-408.

Islam, M. M. \& Habiba, U. (2015). Use of social media in marketing of library and information services in Bangladesh. DESIDOC Journal of Library and Information Technology, 35(4), 299-303.

Jadhav, V. G. (2014). Application of social networking services (SNS) for library collaboration: An exploratory study. International Research: Journal of Library and Information Science, 4(1), 121-129. Retrieved from http://irjlis.com/wp-content/uploads/2014/06/10-IR174.pdf

Kaplan, A. M. \& Haenlein, M. (2010). Users of the world, unite !: The challenges and opportunities of social media. Business Horizons 53, 5968. http://doi:10.1016/j.bushor.2009.09.003

Kaushik, A. (2016). Use of SNS tools and services by LIS professionals for libraries: A survey. DESIDOC Journal of Library \& Information Technology, 36(5). 284-290.

Kripanont, N. (2007). Examining a technology acceptance model of internet usage by academics within Thai Business Schools (Unpublished doctoral dissertation). Retrieved from http://vuir.vu.edu.au/1512/1/Kripanont.pdf

Lane, M., \& Coleman, P. (2012). Technology ease of use through social networking media. Journal of Technology Research, 3, 1-12. Retrieved from http://citeseerx.ist.psu.edu/viewdoc/download?doi=10.1.1.467.7660\&rep=rep1\&type=pdf

Mishra, C. (2008). Social networking technologies (SITs) in digital environment: Its possible implications on libraries. NCDDP. Retrieved from http://eprints.rclis.org/16844/1/Social\%20networking\%20in\%20Library.pdf

Palmer, J. C. and Stickland, J. (2017). Academic social networking websites: A guide to managing your online presence. Retrieved from http://www.apa.org/science/about/psa/2017/02/academic-social-networking.aspx

Priolkar, S.A. \& Kumbhar, S.S. (2014). Use of social networking sites by library professional in the institute Libraries: A study. Paper presented at Application of Information Technology in Library and Information Sciences conference, BVU AKIMSS, Solapur. https://doi.org/ 10.13140/2.1.4994.6401 
Richter, D., Riemer, K., vom Brocke, J., \& Grobe, B. (2009). Internet social networking- Distinguishing the phenomenon from its manifestations in web sites. Proceedings of the 17th European Conference on Information Systems (ECIS), Italy 2-13. Retrieved from http://aisel.aisnet.org/ecis2009/331

Sahoo, D. R. \& Sharma, D. (2015). Social networking tools for library services. International Journal of Innovative Science, Engineering and Technology, 2(3), 69-71. Retrieved from http://ijiset.com/vol2/v2s3/IJISET_V2_I3_114.pdf

Suraweera, N. S., Razali, N., Chouhan, L. B., Tamang, N., Hubilla, A. M. K. U., Ratnayake, A. M., ... \& Mahesar, S. N. (2010, August). Value of social networking in libraries and information organizations in Asia and Oceania. World Library and Information Congress: 76th IFLA General Conference and Assembly, Gothenburg. Retrieved from http://conference. ifla. org/past/2010/145-suraweera-en. pdf

Taylor \& Francis. (2014). Use of social media by the library: Current practices and future opportunities. Retrieved from http://www.tandf.co.uk/journals/access/white-paper-social-media.pdf

Zohoorian-Fooladi, N., \& Abrizah, A. (2014). Academic librarians and their social media presence a story of motivations and deterrents. Information Development, 30(2), 159-71. 